\title{
Are photocatalytic processes effective for removal of airborne viruses from indoor air? A narrative review
}

\author{
Ali Poormohammadi ${ }^{1} \cdot$ Saeid Bashirian ${ }^{2} \cdot$ Ali Reza Rahmani ${ }^{3} \cdot$ Ghasem Azarian $^{3} \cdot$ Freshteh Mehri $^{4}$ \\ Received: 15 March 2021 / Accepted: 7 June 2021 / Published online: 14 June 2021 \\ (C) The Author(s), under exclusive licence to Springer-Verlag GmbH Germany, part of Springer Nature 2021
}

\begin{abstract}
A wide variety of methods have been applied in indoor air to reduce the microbial load and reduce the transmission rate of acute respiratory diseases to personnel in healthcare sittings. In recent months, with the occurrence of COVID-19 pandemic, the role of portable ventilation systems in reducing the load of virus in indoor air has received much attention. The present study delineates a comprehensive up-to-date overview of the available photocatalysis technologies that have been applied for inactivating and removing airborne viruses. The detection methods for identifying viral particles in air and the main mechanisms involving in virus inactivation during photocatalysis are described and discussed. The photocatalytic processes could effectively decrease the load of viruses in indoor air. However, a constant viral model may not be generalizable to other airborne viruses. In photocatalytic processes, temperature and humidity play a distinct role in the inactivation of viruses through changing photocatalytic rate. The main mechanisms for inactivation of airborne viruses in the photocatalytic processes included chemical oxidation by the reactive oxygen species (ROS), the toxicity of metal ions released from metal-containing photocatalysts, and morphological damage of viruses.
\end{abstract}

Keywords Airborne virus · Corona $\cdot$ Virus $\cdot$ Photocatalyst $\cdot$ Air purifier

\section{Introduction}

Nowadays, with growing concerns about viral pandemics in the last year, and the importance of ventilation systems in reducing the transmission of these diseases, there is a growing

Responsible Editor: Sami Rtimi

Ghasem Azarian

gh_azarian@yahoo.com; g.azarian@umsha.ac.ir

$\checkmark$ Freshteh Mehri

freshteh_mehri@yahoo.com

1 Center of Excellence for Occupational Health, Research Center for Health Sciences, School of Public Health, Hamadan University of Medical Sciences, Hamadan, Iran

2 Department of Public Health, School of Health, Social Determinants of Health Research Center, Health Sciences \& Technology Research Institute, Hamadan University of Medical Sciences, Hamadan, Iran

3 Research Center for Health Sciences, Hamadan University of Medical Sciences, Hamadan, Iran

4 Nutrition Health Research Center, Health Sciences \& Technology Research Institute, Hamadan University of Medical Sciences, Hamadan, Iran interest in using advanced oxidation systems to purify the indoor air of medical, hospital, and public settings (HabibiYangjeh et al. 2020). Many studies have identified SARSCov-2 in air samples that highlight its airborne potential (Abbasipour et al. 2014). In this regard, variety ventilation systems are used to ventilate confined indoor spaces. Heating, ventilation, and air-conditioning (HVAC) systems as a well-known mechanical air cleaners are applied to provide appropriate temperature and humidity and clean air in indoor settings. HVAC systems provide clean air by passing air through different filters such as fiberglass, cotton or polyester, and high-efficiency particulate air (HEPA) filters. In recent months, with the occurrence of COVID-19 pandemic, the role of portable ventilation systems in reducing the load of virus in indoor air has received much attention. The use of conventional filters in these air purifiers cannot remove particle-like viruses from air and are generally used for the removal of odors and larger particles. In this regard, adding a photocatalyst unit to the commercial HVACs is proposed for enhancing the microbial retention capability.

Nowadays, there is a growing interest in the use of advance oxidation processes (AOPs) for the removal of air pollutants. In these processes, active radicals play a key role in pollutant 
degradation, while the air stream is passing through the reactor. The main limitations of the most AOPs for the removal of air pollutants are associated with the short contact time of the pollutants in the reactor. Among the AOPs, photocatalytic processes have been severally used an efficient method for the removal of organic pollutants present in aqueous and gas phases (Rahimi et al. 2016). Until now, the efficiency of these processes has been tested for a wide range of air pollutants, such as pesticides, dyes, and volatile organic compounds (VOCs) (Abdennouri et al. 2016; Mamaghani et al. 2017). Despite the importance of photocatalytic processes in the removal of biological contaminants in indoor air, few studies have been focused on their applicability and efficiency. This might be related to the difficulties in identification and quantitative measurement of biological agents, especially viruses in air. In this regard, in the present study, with respect to HabibiYangjeh et al.'s study (Habibi-Yangjeh et al. 2020) on the heterogeneous photocatalytic disinfection of waterborne, airborne, and foodborne viruses, we focused on the last photocatalysis processes for the removal of viruses from indoor air. Table 1 presents the photocatalytic processes that have been used for the removal of different viruses in air streams.

\section{Type of process}

Todays, photocatalytic processes are commonly used as promising technology for the degradation and removal of organic pollutants from the environments. There is a wide variety of photocatalytic processes that are mostly used for aqueous media in a batch reactor. In this regard, the application of such processes for purifying air streams is still a challenge due to the very short exposure time. In the application of photocatalytic processes for the removal of organic compounds, the air stream containing the pollutants is passed through a photocatalyst filter, which results in a very short contact time between the pollutant molecules and the photocatalyst surface. This is considered a major limitation for the application of these technologies in air. Previous studies have showed that the photocatalytic processes are able to remove the VOCs from air streams with a limited efficiency in the range 50-70\% depending on the air flow rate and used source light (Cao et al. 2000; Liang et al. 2010). However, many efforts have been made to improve the efficiency of the photocatalytic processes for air purifying (Long et al. 2012; Samarghandi et al. 2017). Due to the advantages of the photocatalytic processes, many researchers have recently focused on the use of ultraviolet (UV) along with catalyst for the inactivation of pathogenic microorganisms in water as an on-site disinfection method (De Vietro et al. 2019; Gerrity et al. 2008). Few studies have investigated the application of these technologies for inactivation of viruses in air. As we know, with growing concerns about viral pandemics in the last year, and the importance of using ventilation systems for reducing the transmission of these diseases, there is an increasing interest in the use of photocatalytic processes for the removal and reducing the load of airborne microbial agents. For this reason, different types of photocatalytic processes can be used for inactivation of viruses in air due to their organic nature as follows:

\section{$\mathrm{TiO}_{2}$ photocatalyst}

As previously mentioned, various materials have been used as photocatalytic, which are typically made of metal oxides, metal sulfides, oxysulfides, oxynitrides, and composites (Sakka 2013). Among them, $\mathrm{TiO}_{2}$ has been more commonly used for the sterilization of microbial agents and organic compounds ( $\mathrm{Li}$ et al. 2018). For instance, in Kim et al.'s study, $\mathrm{TiO}_{2} / \mathrm{UV}$ photocatalyst showed the highest activity for inactivation of airborne MS2 viruses (Kim and Jang 2018). In order to use $\mathrm{TiO}_{2}$ as a photocatalyst in air purifiers, it should be used in the form of a filter similar to other filter type, which provides enough surfaces for passing a determined volume of polluted air and trapping pollutants in the air stream. For this reason, in the Kim et al.'s study, four types of catalyst frame shapes, including two mm-pleated, five mm-pleated, spiral, and flat sheet types, were applied with a thickness of $0.2 \mathrm{~mm}$ of titanium sheets, and it was found that the $2 \mathrm{~mm}$ pleated catalyst offered the highest efficiency for the inactivation of airborne MS2 viruses (Kim and Jang 2018). They also used a vacuum UV (VUV, wavelength $\leq 200 \mathrm{~nm}$ ) for the photocatalysis of the target virus. The VUV refers to the wavelength range below $\approx$ $200 \mathrm{~nm}$. In the vacuum UV range, light is strongly absorbed in air and thereby can improve the performance of the photocatalytic process for air applications. In this regard, a previous study reported a higher disinfection efficacy for vacuum UV in comparison with UV light on Bacillus subtilis spores (Wang et al. 2010). Zan et al. (2007) also investigated the efficiency of nano- $\mathrm{TiO}_{2}$ particles and $\mathrm{TiO}_{2}$-coated ceramic plates as photocatalytic processes on the inactivation of hepatitis B virus (HBV). However, in the Zan et al.'s study, HBV surface antigen in aqueous solution was removed using the photocatalytic process, and it cannot be generalized to the origin virus. They reported that both $\mathrm{TiO}_{2}$ suspension and $\mathrm{TiO}_{2}$-coated ceramic plates were capable of destroying most HBV antigens under weak ultraviolet light, weak sunlight, or indoor sunlight (Zan et al. 2007).

In another study, a thin film of $\mathrm{TiO}_{2}$-coated glass (T3 sample, $50 \times 50 \mathrm{~mm})$ along with a low intensity of UV-A $(0.01$ $\mathrm{mW} \mathrm{cm}{ }^{-2}$ ) was successfully applied for inactivation of influenza virus (Nakano et al. 2012a). $\mathrm{TiO}_{2}$ in combination with other compounds such as copper(II) has been applied for the inactivation of airborne viruses. For instance, in a recent study, $\mathrm{Cu}(\mathrm{II})-\mathrm{TiO}_{2}$ nanocomposite was synthesized and used for viral inactivation in air, which showed suitable antiviral 


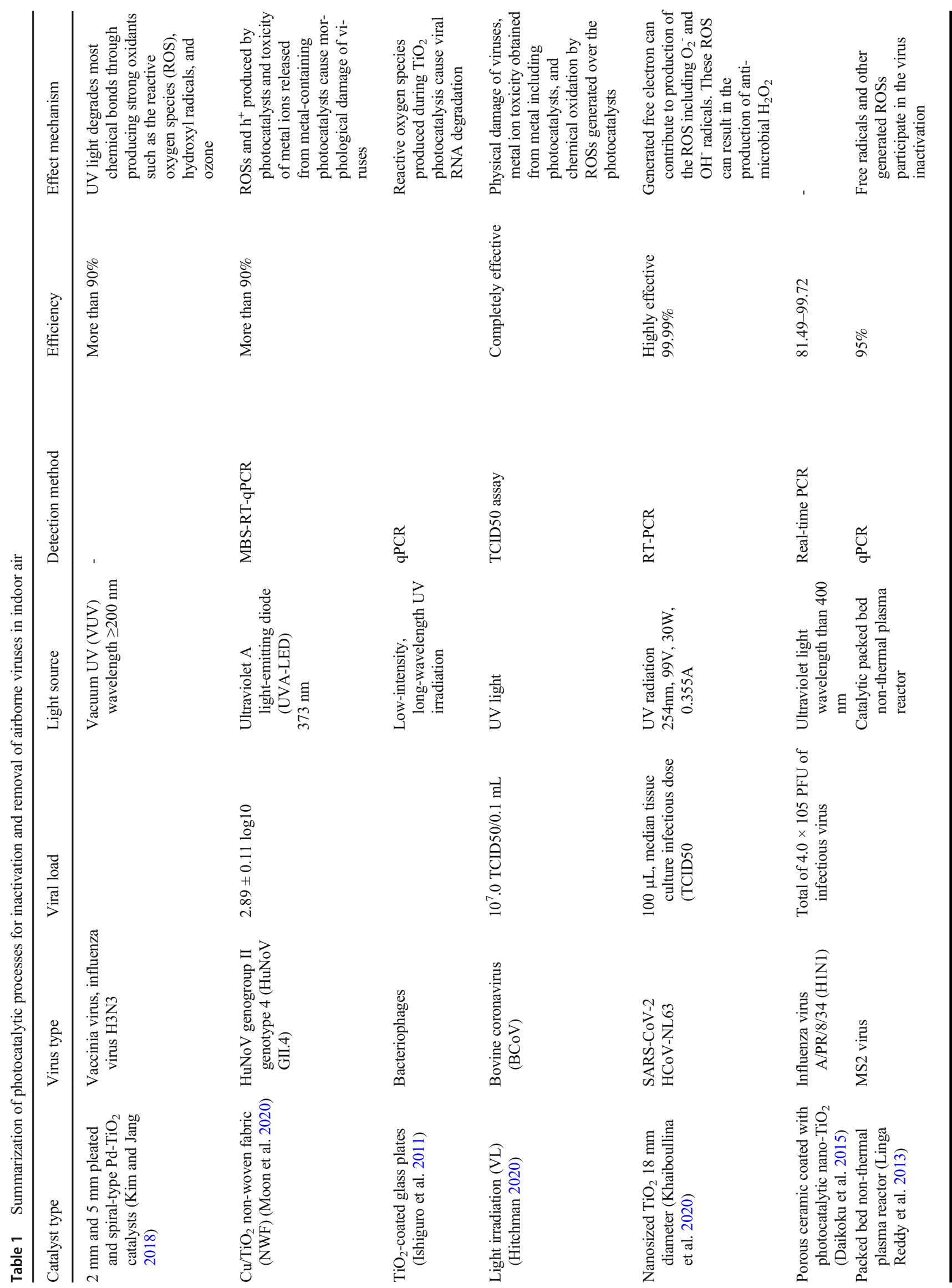




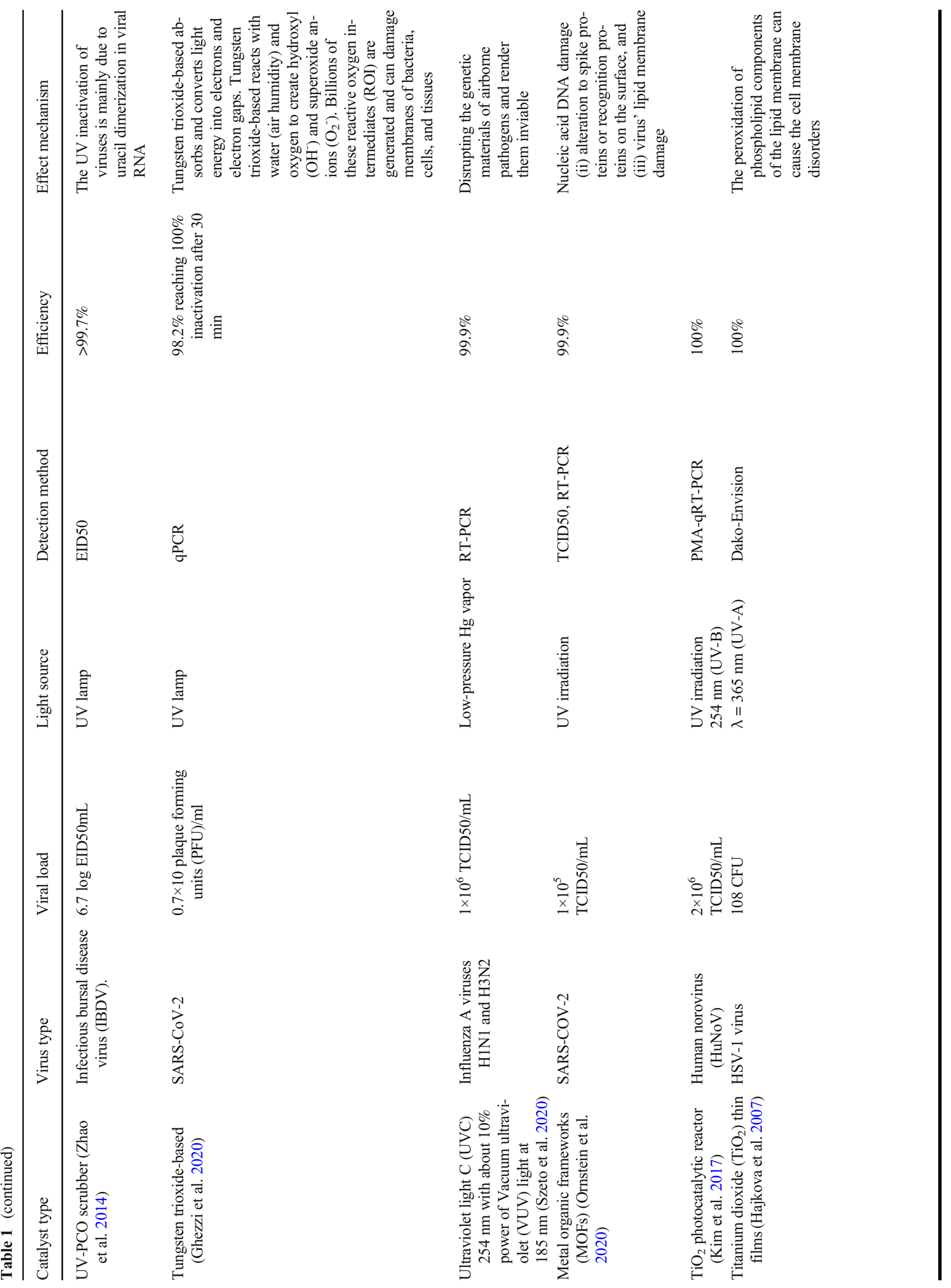


activity (Liu et al. 2015). Recently, many efforts have been made to improve the photocatalytic characteristics of commercial $\mathrm{TiO}_{2}$ as a photocatalyst for inactivation of microbial agents. In a related study, Ahmed et al. introduced a simple method for the synthesis of anatase $\mathrm{TiO}_{2}$ quantum dots using a single step microwave-hydrothermal method, which offered a higher energy gap compared to the commercially available anatase $\mathrm{TiO}_{2}$ nanoparticles. They also reported an increase in the absorbance of ultraviolet light for superior photocatalytic inactivation ability of $E$. coli (Ahmed et al. 2019). In Daikoku et al.'s study on the inactivation of aerosolassociated influenza by photocatalysis using an air cleaner and the porous ceramic substrate, due to the use of porous ceramic coated with nanoTiO ${ }_{2}$, the viral inactivation efficiency of photocatalysis was greatly attributed to the surface area of the used coated ceramic, and the photocatalytic air cleaner showed a high efficiency for the decomposition of organic chemicals including acetaldehyde and dioxins and inactivation of aerosol-associated influenza virus in air stream (Daikoku et al. 2015). Moreover, Nakano et al. also reported that $\mathrm{TiO}_{2}$ thin film could disinfect influenza virus through degradation of viral proteins, in which this inactivation effect depended on the UV irradiation time and its intensity (Nakano et al. 2012b). Therefore, it can be concluded that $\mathrm{TiO}_{2}$ thin film can be successfully used for disinfection of the influenza virus in the air, which can be also used for other airborne viruses and hinder viral transition through air. Moreover, doping $\mathrm{TiO}_{2}$ with other metals like $\mathrm{Pt}, \mathrm{Ag}, \mathrm{Pd}$, and $\mathrm{Au}$ has been recently introduced as effective strategy to enhance its photocatalytic activity. The application of metal nanoparticle provides a high specific surface area to generate special barrier, which results in an increase in the photocatalytic activity of the basic $\mathrm{TiO}_{2}$ through the improvement of charge separation rate. It has been also reported that in the decoration of $\mathrm{TiO}_{2}$ with $\mathrm{Au}$ and $\mathrm{Ag}$, the localized surface plasmon resonance as an additional effect leads to a strong absorption of the visible light, which improves the photocatalytic activity of the decorated $\mathrm{TiO}_{2}$ (Yu et al. 2017).

\section{Ag photocatalyst}

Silver (Ag) has been widely used as an antibacterial materials due to its high surface area and chemo-physical properties (Marambio-Jones and Hoek 2010). $\mathrm{Ag}^{+}$and silver nanoparticles can inactivate the viruses and denature their enzymes through the reaction with sulfhydra, amino, carboxyl, phosphate, and imidazole groups. In this case, Joe et al. (2016) synthesized silver nanoparticles using spark discharge generation (SDG) system and then coated the particles onto the air filter surface to provide antiviral ability (Joe et al. 2016). SDG is one of the mechanical methods that uses a high voltage to a pair of close-set silver electrodes, in which a spark is produced between the two electrodes. In this system, under 
the effect of the electric field, the accelerated ions and electrons affect the surface of the silver node and results in the vaporization of the electrode surface. The metallic vapors cool downstream from the spark. Eventually, nucleation condensation and coagulation of the silver nanoparticles occurred (Byeon et al. 2008; Joe et al. 2016). In addition, silverdoped titanium dioxide $\left(\mathrm{Ag} / \mathrm{TiO}_{2}\right)$ nanocomposites with various silver contents have been also developed for oxidation of microbial agents. Moongraksathum et al. reported that the presence of silver on $\mathrm{TiO}_{2}$ significantly improved the virucidal effects (greater than 99.99\%) under UV-A irradiation (Moongraksathum et al. 2019). Therefore, coating Ag with $\mathrm{TiO}_{2}$ can be used as absolution for improving the photocatalytic properties of $\mathrm{Ag}$ in the inactivation of viral particles in air. For instance, Mehdizadeh and Tavangar showed that the presence of $1.5 \% \mathrm{Ag}$ coated on $\mathrm{N} / \mathrm{TiO}_{2}$ (with $2: 1$ mole ratio) resulted in the highest activity under visible and ultraviolet irradiation in the photocatalytic processes (Mehdizadeh and Tavangar 2017). Moreover, Liga et al. demonstrated that the inactivation rate of MS2 was enhanced by more than 5-fold through silver-doped titanium dioxide nanoparticles (nAg/ $\mathrm{TiO}_{2}$ ), depending on the base $\mathrm{TiO}_{2}$ material, and the inactivation efficiency increased with increasing silver content. They also reported that the inactivation efficiency of MS2 virus in drinking water using the $\mathrm{nAg} / \mathrm{TiO}_{2}$ nanoparticles was attributed to increased production of hydroxyl-free radicals under the effect of UV-A irradiation provided by four $8 \mathrm{~W}$ UV-A lamps (in a wavelength range 315-400 nm) (Liga et al. 2011). Therefore, it can be concluded by doping $\mathrm{TiO}_{2}$ with $\mathrm{Ag}$ nanoparticles; a synergic effect occurs between them for inactivating viruses under UV radiation. It has been also reported that $\mathrm{TiO}_{2}$ doped with silver causes a slight increase in virus adsorption on the catalyst surface and also increases the photocatalytic inactivation of viruses through the increase of the production of hydroxyl-free radicals (Liga et al. 2011). It should be noted that most of the mentioned studies have focused on the photocatalytic inactivation of viruses in water and aqueous solutions, and very few research have investigated the effects of such processes for inactivation of viral agents in air.

\section{Cu photocatalyst}

Some recent studies have evaluated the role of copper $(\mathrm{Cu})$ in the photocatalysis of various organic compounds in air (Arana et al. 2005; Papadaki et al. 2019; Tri et al. 2019; Wu et al. 2018). It has been reported that the presence of $\mathrm{Cu}$ in the catalyst surface could modify the interactions of the organic pollutants with the catalysts surface and thereby improves the process efficiency (Araña et al. 2005). $\mathrm{Cu}$ is most commonly used as doping agent with $\mathrm{TiO}_{2}$ and $\mathrm{ZnO}$ photocatalyst in order to improve their photocatalytic activity. In a related research, it was reported that the $\mathrm{Cu}$-doped $\mathrm{ZnO}$ exhibits 3.5- fold higher photocatalytic activity compared to pure corn seed-shaped $\mathrm{ZnO}$ (Kadam et al. 2017). Cu has also been used in $\mathrm{Cu}-\mathrm{TiO}_{2}$ nano-fibers under visible light for inactivation of viral agents, in which the $\mathrm{Cu}-\mathrm{TiO}_{2}$ nano-fibers offered a suitable efficiency for the inactivation of bacteriophage $\mathrm{f} 2$ under visible light (Zheng et al. 2018). Cuprous oxide $\left(\mathrm{Cu}_{2} \mathrm{O}\right)$ as a semiconductor with optical-band-gap absorption has been also applied as a promising photocatalyst (Singh et al. 2018). To the best of our knowledge, until now, there has been no study evaluating the use of $\mathrm{Cu}_{2} \mathrm{O}$ as photocatalytic for the inactivation of virus in air. Based on the previous studies, the efficient antiviral properties of $\mathrm{Cu}_{2} \mathrm{O}$ can convert it as a suitable alternative for rapid inactivation of viral agents in air stream with continuous flows through photocatalytic processes. $\mathrm{CuxO} / \mathrm{TiO}_{2}$ photocatalyst has been also applied as an antivirus agent through denaturalizing the protein of the virus in the photocatalytic oxidation process (Abidi et al. 2019). $\mathrm{Cu}$ (II) species in the $\mathrm{CuxO}$ can act an electron acceptor through photo-induced interfacial charge transfer, resulting in the production of $\mathrm{Cu}(\mathrm{I})$ species with antivirus activity and holes with high oxidation potential under visible light irradiation in the valence band similar to $\mathrm{TiO}_{2}$. The $\mathrm{CuxO} / \mathrm{TiO}_{2}$ photocatalyst can maintain its antiviral effect under dark conditions, due to the remaining active $\mathrm{Cu}$ (I) species. Hence, it has been suggested that the proposed $\mathrm{CuxO} / \mathrm{TiO}_{2}$ photocatalyst can decrease the risk of transmission of viral infection in indoor air by applying such coating photocatalyst (Miyauchi et al. 2020).

\section{Type of virus}

Due to the difficulty in quantifying viruses in the air, it is very difficult to determine the efficiency of photocatalytic processes to remove and inactivate airborne viruses. Because, so far, no standard method has been introduced for the sampling and detection of virus in air streams, little attention has been paid to the sampling and determination of viruses in air. This limitation has been well addressed in our previous paper (Rahmani et al. 2020). On the other hand, most of the airborne viruses are associated with dangerous respiratory diseases such as SARS-associated coronaviruses, which makes it difficult to work with them at laboratory environments. In this regard, bacteriophages have received much attention from researchers worldwide as an indicator of airborne viruses. Bacteriophages as a group of viruses can infect and kill bacteria without adverse health effects on human or animal (Principi et al. 2019). Moreover, previous studies showed that bacteriophages are appropriate model organisms for virus emergence research due to their characteristics (Dennehy 2009). As can be seen in Table 1, some previous studies have also evaluated the effectiveness of photocatalytic processes for the removal of bacteriophages as a viral model in indoor air. For instance, in Kim et al.'s study, $\mathrm{TiO}_{2} / \mathrm{UV}$ photocatalyst 
was applied for inactivation of airborne MS2 viruses (Kim and Jang 2018). In another study, sealed UV-C flow reactors operating with fluences near at a wavelength of $253 \pm 1 \mathrm{~nm}$ were efficiently applied for the inactivation of coronaviruses in indoor air. In the mentioned study, it was concluded that that UV-C flow reactors can efficiently inactivate coronaviruses in air and hence can be used in HVAC ducts or recirculating air purifiers (Cho et al. 2003). However, the short contact time during the passage of high air flow in these processes is considered a major limitation. In a previous study, a highintensity UV cell with a length of $91.4 \mathrm{~cm}$ consisted of a highly reflective inner surface and a longitudinally extending helical baffle system was applied for the inactivation of several viruses, and it was found that inactivation rates of greater than $99.9 \%$ were obtained for the studied viruses including influenza, Sindbis, Coxsackie, and vaccinia viruses. Moreover, a slightly less efficiency was observed for adenovirus that was $96.8 \%$. In this case, the inactivation efficiency of the proposed UV based system decreased with an increase in the flow rate from 100 to $200 \mathrm{ft}^{3} / \mathrm{min}$ (Jensen 1964). Therefore, the photocatalytic processes offer various performances for the inactivation of viruses in air, and therefore, a constant viral model may not be generalizable to other airborne viruses.

\section{Viral load}

Viral load as the initial pollutant concentration can affect the performance of photocatalytic processes. Many studies have investigated the effect of initial load of organic pollutants (e.g., benzene, toluene, and other pollutants) on the photocatalytic process efficiency (Al-Sabahi et al. 2017; Einaga et al. 2004). Regarding the effect of initial viral load, Yu et al. used a reactor equipped with two ultraviolet lamps and $\mathrm{a} \mathrm{TiO}_{2}$ filter at $365 \mathrm{~nm}$ wavelength for the removal of various types of airborne microorganisms and showed that the photocatalytic filter was able to remove about $36 \%$ of the airborne phages with an initial viral load of $8.7 \times 10^{4}-1.2 \times 10^{7}$. They also reported that the single UVA at a wavelength of $365 \mathrm{~nm}$ (without $\mathrm{TIO}_{2}$ filter) did not offer a significant efficiency and therefore cannot be used in single mode for inactivation of airborne virus in continuous-flow rate reactors. Similar results have been reported by other studies such as Jensen et al.'s study (Jacoby et al. 1998). Moreover, in Nakano et al.'s study, it was found that despite the partial intensity of UVA, a $4 \log _{10}$ decrease was observed in the viral load during the illumination time. As mentioned above, the UVA along with a thin layer of $\mathrm{TiO}_{2}$ can also be useful for disinfection of air containing airborne viruses. Moreover, Qiao et al. reported a higher than 3$\log$ reduction in the concentration of in viable coronavirus aerosol under UV-C irradiation (Qiao et al. 2020c). Ghezz et al. showed that a photocatalyst system based on a filter combining tungsten trioxide-based photocatalysis and an antiviral fabric treated-copper nanocluster could decrease the load of SARS-Cov-2 by $1.5 \log _{10}$ after $30 \mathrm{~min}$ (Ghezzi et al. 2020).

\section{Environmental factors}

\section{Air flow rate}

In air disinfection, air velocity is an important parameter that affects the performance of biological aerosol removal. The airflow in terms of velocity and air distribution should provide effective contact between microbial agents such as viruses with optical photons and radicals responsible for the destruction of these agents in air stream. At high air velocities, the residence time of the bioaerosols in the reactor is not sufficient to inactivate them during passing through the filter installed in the photocatalytic reactor (Lin and $\mathrm{Li}$ 2003). In order to inactivate airborne agents, they first should be trapped on the filter surface $\left(\mathrm{TiO}_{2}, \mathrm{Ag}, \mathrm{Cu}\right.$, and other composite coated filters) and then inactivated under the effect of UV or other kind of light irradiation. In this case, the filter penetrations of microorganisms also increased as face velocities increased (Cho et al. 2003). Hence, the flow velocity is proportional to the flow rate and can mainly affect the photocatalytic process performance. Recently, VUV has been introduced as a very effective light source for inactivation of viruses at short contact times (Habibi-Yangjeh et al. 2020). In Kim and Jang's study, photocatalytic processes were capable of removing $90 \%$ of MS2 (as an airborne virus) using the $\mathrm{Pd}-\mathrm{TiO}_{2} / \mathrm{VUV}$ system at very short irradiation times of about $0.009 \mathrm{~s}$ with a flow rate of $33 \mathrm{~L} / \mathrm{min}$. In many studies, the effect of air velocity in photo reactors has been investigated below $0.5 \mathrm{~m} / \mathrm{s}$, and in some studies, it was investigated even at $0.05 \mathrm{~m} / \mathrm{s}$ (Chen et al. 2009). In this regard, Jost et al. designed an optical reactor to purify air contaminated with existing Legionella pneumophila bacteria at high airflow velocities in the range $2.7-4.1 \mathrm{~m} / \mathrm{s}$, with a disinfection efficiency of $93 \%$ in a single pass mode (Josset et al. 2007).

\section{Reactor temperature}

A review of the literature showed that most photocatalytic processes have been used to remove viruses at room temperature (Goswami et al. 1997). Until now, no studies have specifically investigated the effect of reactor temperature on the photocatalytic performance for the inactivation of airborne viruses and even other airborne microbial agents. The effect of temperature is also less studied in continuous-flow reactors for organic compounds. Goswami et al. had stated that temperature does not affect the UV disinfection process, and the temperature rise caused by the UV lamps in the duct did not 
play a significant role in the inactivation of bacteria (Goswami et al. 1997). However, some studies highlighted the role of air temperature as an effective factor on the photocatalytic performance of different materials. In heat-based processes, high temperatures can cause damage and death to microorganisms, through destructing proteins and disrupting the structure of polypeptides. However, its disadvantage is the high energy consumption for applying thermal energy at high temperatures (Cho et al. 2003; Lin and Li 2003). Therefore, photocatalytic processes can be operated at low temperatures and hence do not require high temperatures and high energy consumption. In general, rising temperature reduces the population of viruses in air, but this phenomenon happens without the use of a photocatalytic process and requires a long contact time. For this reason, the use of combined processes along with UV irradiation can efficiently inactivate viruses and other microbial agents at shorter contact times. The use of higher temperatures can also accelerate the degradation process. In a recent study on the removal of MS2 (as an indicator if airborne virus) using VUV photocatalysis, when viruses were exposed to VUV irradiation, the inactivation rate of MS2 at $25^{\circ} \mathrm{C}$ was higher than at $4{ }^{\circ} \mathrm{C}$. However, the normal deactivation rate after $12 \mathrm{~h}$ was reported to be $53 \%$ and $55 \%$ at $4^{\circ} \mathrm{C}$ and 25 ${ }^{\circ} \mathrm{C}$, respectively (Habibi-Yangjeh et al. 2020). This study has been conducted on waterborne viruses and may not be generalizable to air. In a recent study, it was also found that by increasing the temperature of the photocatalytic materials, the photocatalytic activity enhanced, indicating the role of reactor temperature in photocatalytic process (Costacurta et al. 2010). Another study reported an increase in the efficiency of photocatalytic oxidation of benzene with increasing reactor temperature up to $45^{\circ} \mathrm{C}$ (Jafari et al. 2019). Due to the greater complexity of the effect of temperature on the virus as an organism, this cannot be generalized to viruses as a general rule. It has been also reported that low temperatures in air in the range $7-8{ }^{\circ} \mathrm{C}$ provide an optimal condition for airborne influenza survival, and their survival decreased with increasing environmental temperature in the range $20.5-24^{\circ} \mathrm{C}$, and then this decrease intensifies at higher temperatures $\left(>30^{\circ} \mathrm{C}\right)$ (Tang 2009).

\section{Relative humidity}

Relative humidity is another important environmental factor affecting the photocatalytic performance through the intervention of water molecules in occupying the free sites on the catalyst surface (Samarghandi et al. 2014). Regarding the effect of relative humidity in air on the virus inactivation, a recent study has reported that there was no determined relationship between coronavirus inactivation and relative humidity in indoor air, and a higher survival rate was observed for SARS-Cov- 2 at $20 \%$ as a low humidity level and its survival rate decreased by increasing the relative humidity from 50 to
$80 \%$ (Harmooshi et al. 2020). Also Koet al et al. demonstrated that a relative humidity of $70 \%$ is suitable for eliminating airborne microorganisms (19). In another study, photocatalytic inactivation of airborne microorganisms using $\mathrm{TiO}_{2}$ coated on fiberglass filter increased by increasing relative humidity between 30 and $80 \%$, while it decreased by decreasing the relative humidity lower than 30\% (Lee 2011). In Yu et al.'s study on the use of photocatalytic of three different types of airborne microorganisms, it was found that the relative humidity causes an increase in the removal efficiency of airborne viruses, and the removal efficiency of phages, as viral model, increased from about 10 to $20 \%$ by increasing relative humidity from 30 to $70 \%$ (Yu et al. 2008). However, they reported an opposite trend for $E$. coli in the proposed photocatalytic process. This difference may be due to the difference in the size of viruses with bacteria, which have higher contact with the $\mathrm{TiO}_{2}$ photocatalyst (Nakano et al. 2012b).

\section{Light sources}

Light source as an agent activating catalyst in the photocatalytic process plays a key role in the removal of pollutants in air stream. In this regard, various light sources such as UV light (subdivided into UV-A, UV-B, and UV-C), visible light, light-emitting diode (LED), and sun light (as a natural light source) have been applied in the photocatalytic processes (De Vietro et al. 2019; Gerrity et al. 2008; Liu et al. 2015). Sunlight as an inexhaustible source has received much attention to be used in photocatalysis processes. When a photocatalyst is irradiated with light source with energy greater than the band gap energy leads to the generation of the formed $\mathrm{e}^{-}-\mathrm{h}^{+}$pairs. These excited holes and electrons with strong energy potentials could migrate to the semiconductor surface for generating highly reactive free radicals or recombining (Tsang et al. 2019). The mechanisms of virus inactivation using photocatalytic processes have been completely described in Habibi-Yangjeh et al.'s study (Habibi-Yangjeh et al. 2020). In this regard, by increasing the energy intensity of the light source, the generation of reactive free radicals from the photocatalyst surface is increased and thereby results in an increase in the inactivation of microbial agents in passing air. However, the band gap of the photocatalyst plays a key role in the feasibility of using a light source. For instance, $\mathrm{TiO}_{2}$ as the most commonly used photocatalyst, due to its advantages such as high chemical stability, low cost, and low toxic, has a limited band gap of $3.2 \mathrm{eV}$, which can be activated under UV-light region. Four to five percent of solar light lies in the UV region [15], while $45 \%$ of solar light lies in the visible light region. Many researches have been conducted to expand the spectral response of $\mathrm{TiO}_{2}$ to the visible light region such as doping with nonmetal, coupled semiconductors, metal deposition, and defect- 
induced visible light active photocatalyst. For example, in Zan et al.'s study, weak ultraviolet light, weak sunlight, or indoor sunlight could activate the $\mathrm{TiO}_{2}$-coated ceramic plates for inactivation of hepatitis B virus (Zan et al. 2007). In Jafry et al.'s study, it was reported that adding silica to $\mathrm{TiO}_{2}$ nanoparticles led to an increase in the band gap of the $\mathrm{TiO}_{2}$ nanoparticles, which increased the $\mathrm{OH}^{*}$ and thereby increased photocatalytic activity of the proposed photocatalyst. In the mentioned study, the silica-doped $\mathrm{TiO}_{2}$ nanoparticles were used for the inactivation of viruses (bacteriophage MS2) (Jafry et al. 2011). It is noteworthy that the addition of silica did not increase the surface area of the resulting photocatalyst, and the higher virus inactivation rate of silica doping $\mathrm{TiO}_{2}$ was reported to be due to the increased adsorption of viruses onto the catalyst and higher generation of $\mathrm{OH}^{*}$, which are responsible for the viral inactivation (Jafry et al. 2011). Nakano et al. also reported that UVA along with $\mathrm{TiO}_{2}$ thin film could disinfect influenza virus through degradation of viral proteins and was successfully used for disinfection of the influenza virus in the air. This inactivation effect depended on time of UV and its intensity (Nakano et al. 2012b). Ghezzi et al. used tungsten trioxidebased photocatalyst and UV irradiation based on a filter combining and an antiviral fabric treated-copper nanocluster for inactivation of SARS-CoV-2 in indoor conditions. Based on their results, the viral load decreased by $98 \%$ after $10 \mathrm{~min}$ and then reached $100 \%$ inactivation after $30 \mathrm{~min}$. They also reported that the SARS-CoV-2 RNA load decreased by 1.5 $\log _{10}$ after $30 \mathrm{~min}$, indicating appropriate performance for inactivation SARS-CoV-2 (Ghezzi et al. 2020). As mentioned earlier, LED has been also applied as light source in photocatalytic systems. In a related study, Doss et al. for the first time introduced LED photocatalytic system with $\mathrm{TiO}_{2} / \beta$-SiC solid alveolar foams for inactivation of airborne viruses like T2 bacteriophage and demonstrated the potential application of LEDs and solid alveolar foam as an effective and costeffective technology for inactivation of airborne virus using photocatalyst. Moreover, Shiraki et al. proposed an air purifier system based on UV-LED for inactivation of the aerosolassociated influenza virus. In this case, they constructed a $\mathrm{TiO}_{2}$-coated aluminum plate under the irradiation of UVLED, showing a high performance for inactivation of the aerosol-associated influenza virus in indoor air (Shiraki et al. 2017).

\section{Virus detection}

Detecting virus in air is still a challenge among researchers. Until now, no valid and general procedure has been introduced for the sampling and detection of virus in air to monitor the performance of different purifier devices. Detecting airborne viruses requires two steps: (1) sampling with a suitable sampler (that have been completely reviewed in our previous paper (Rahmani et al. 2020) and (2) identifying trapped viruses in samplers using molecular amplification methods such as polymerase chain reaction (PCR) and reverse transcriptase PCR (RT-PCR). In this regard, in this section, we reviewed the detection methods for the determination of viral load in the photocatalysis processes. The Median Tissue Culture Infectious Dose (TCID50) assay is a common method for quantifying the number of infectious virus particles. The TCID50 assay as an endpoint dilution assay can determine the point in which $50 \%$ of the cells in the culture are infected, and hence it can offer a ratio of infected and uninfected cells. The TCID50 assay method is based on the addition of a serial dilution of the virus sample to cells in a 96-well plate format. The assay results are determined based on the morphological changes of upon infection with the virus or cell death. In this regard, after a determined time, the wells are checked and scored to determine the presence or absence of cytopathic effects. Therefore, the dilution of virus at which $50 \%$ of the wells are infected is determined by plotting graphs and calculating the percentage of infected cells at each dilution (Smither et al. 2013). Consistent with the application of this method for determination of viral load in air, Yoshizawa et al. used the TCID50 assay on confluent monolayers of HRT-18G cells in 96-well plates for quantifying bovine coronavirus in suspension and investigating the efficiency of photocatalytic process for inactivation of this virus (Yoshizawa et al. 2020). It is noteworthy that this method has been only used for viral suspensions. In Kormuth et al.'s study, the TCID50 was directly used for determination of influenza virus infectivity in aerosols and droplets independent, in which virus stocks were prepared in MDCK cells until the onset of cytopathic effect (Kormuth et al. 2018).

As can be seen in Table 1, molecular amplification methods such as PCR and RT-PCR have been commonly used for the detection of airborne viruses to evaluate the performance of different photocatalytic processes. For instance, in Ghezzi et al.'s study, in the application of tungsten trioxide-based photocatalysis for rapid inactivation of SARS-Cov-2 in air, qPCR was applied for measuring the viral RNA content in the air taken samples (Ghezzi et al. 2020). They have also used viral plaque assay for counting infectious viral particles in air. The viral plaque assay is a classic method for counting and determining the virus particles in air. In this regard, Yin et al. introduced the plague assay as a simple and highly repeatable method for enterovirus (Yin et al. 2015). In this method that is based on the formation of clear plagues on a 24-well plate or a 96-well plate are visible with naked eyes without immunostaining (Yin et al. 2015). In Qiao et al.'s study, RT-PCR along with measurement of fluorescein concentrations (doped into the nebulized aerosol) was applied for determining the performance of HVAC systems for removing and inactivating coronaviruses in air (Qiao et al. 2020b). 


\section{Mechanism of photocatalysis}

After introduction photocatalysis as an effective and efficient system for the inactivation of viruses for the few attention first time by Sierka and Sjogren in 1994, various scientists made many efforts to justify its mechanism. Herein, we discuss the effect of the single photocatalysts in the virus inactivation. $\mathrm{Cu}$ as one of the most commonly used photocatalysts is able to inactive microbial agents even in dark. However, the illuminated catalyst can accelerate microbial inactivation rate. Antimicrobial effects of $\mathrm{Cu}$ occurred due to (a) surface contact killing, (b) $\mathrm{Cu}$ ions, and (c) chemical oxidation by generated ROSs in the presence of $\mathrm{O}_{2}$ (Rtimi et al. 2019). Also, Ag as a well-known antimicrobial agent can inactivate germs by only releasing silver ions and penetrating into the microbial agents. It has been also reported that $\mathrm{Ag}$ can inactivate bacteria and other pathogens through oligodynamic effect of metals. It has been also reported that Ag shows a higher toxicity towards bacteria, fungi, and viruses compared with mammalian cells (Prasher et al. 2018). Moreover, in the presence of moisture, Ag particles release highly oxidative Ag ions, which can complex with DNA and RNA of microorganisms and hence inhibit their replication. Previous studies have even reported a different efficiency for various size, shape, and concentration of Ag particles.

There is limited information regarding the mechanisms of $\mathrm{TiO}_{2}$ antimicrobial activity. However, it has been well studied that $\mathrm{TiO}_{2}$ can inactivate microorganisms through oxidative attack on the outer or inner cell membrane of the microbial agents (Barbas Arribas and Rojo Blanco 2015). In this regard, Moon et al. investigated virucidal effects of a $\mathrm{Cu} / \mathrm{TiO}_{2}$ nonwoven fabric (NWF) on viral particles of $\mathrm{HuNoV}$ genogroup II genotype 4 (HuNoV GII.4) under irradiation of UVA-LED. The results showed that the proposed system degraded $\mathrm{HuNoV}$ viral particles in the air samples (Moon et al. 2020). Kim et al. indicated UV-assisted $\mathrm{TiO}_{2}$ photocatalysis, and high hydrostatic pressure treatments were effective for inactivating internalized murine norovirus and the infectious viral content (Kim et al. 2017). Photocatalysis using semiconductor has been proven to effectively degrade a vast variety of pollutants (Fig. 1). The suggested three major mechanisms for viral inactivation in photocatalysis included chemical oxidation by ROS, the toxicity of metal ions released from metalcontaining photocatalysts, and morphological damage of viruses by sharp edges of two-dimensional nano-structural photocatalysts (Kumar and Devi 2011). However, the detailed mechanism of photocatalyst is different for different pollutants. It is well known that semiconductor is characterized by a band energetic structure, with a band gap between the lower valence band or negative electrons (e-: electron hole), entirely filled with electrons, and the unoccupied, higher energetic conduction band or positive holes $(\mathrm{h}+)$ that with a different process generates superoxide anions $\left(\mathrm{O}_{2}+\mathrm{e}^{-} \rightarrow \mathrm{O}_{2}^{-}\right)$and hydroxyl radicals $\left(\mathrm{OH}^{-}+\mathrm{h}^{+} \rightarrow \mathrm{OH}^{*}\right)$ in the surface of semiconductor (Kumar and Devi 2011; Visai et al. 2011), following by the generation of highly $\mathrm{ROS}$ like $\mathrm{OH}, \mathrm{O}_{2}^{-}, \mathrm{h}^{+}$, and $\mathrm{HO}_{2}$ with high oxidation potential, which can reduce inorganic contaminants to nontoxic ions, oxidize organic contaminants into $\mathrm{CO}_{2}$ and inorganic ions, and inactivate microorganisms without producing noxious compounds (Kanakaraju et al. 2018; Yang et al. 2014). It is also noteworthy that the generation of ROSs from the mentioned photocatalytic processes can destroy the shell and/or capsid of viruses, resulting in the release of genetic materials, minerals, and proteins inside viruses; also organic compounds available in the structure of viruses could be completely mineralized, which causes virus inactivation (Candiani and Soliani n.d.). Many researchers have proposed diverse mechanisms by different photocatalysis processes for inactivation of viruses. Regarding the Ag photocatalysis for the inactivation of airborne viruses, Ag reacts with oxygen and relative humidity in air and causes the formation of $\mathrm{AgOH}$. Then, the generated $\mathrm{AgOH}$ with a 2-3 atomic layer, on the catalyst surface, decomposes to $\mathrm{Ag}_{2} \mathrm{O}$ as follows:

\section{Photocatalysis processes}

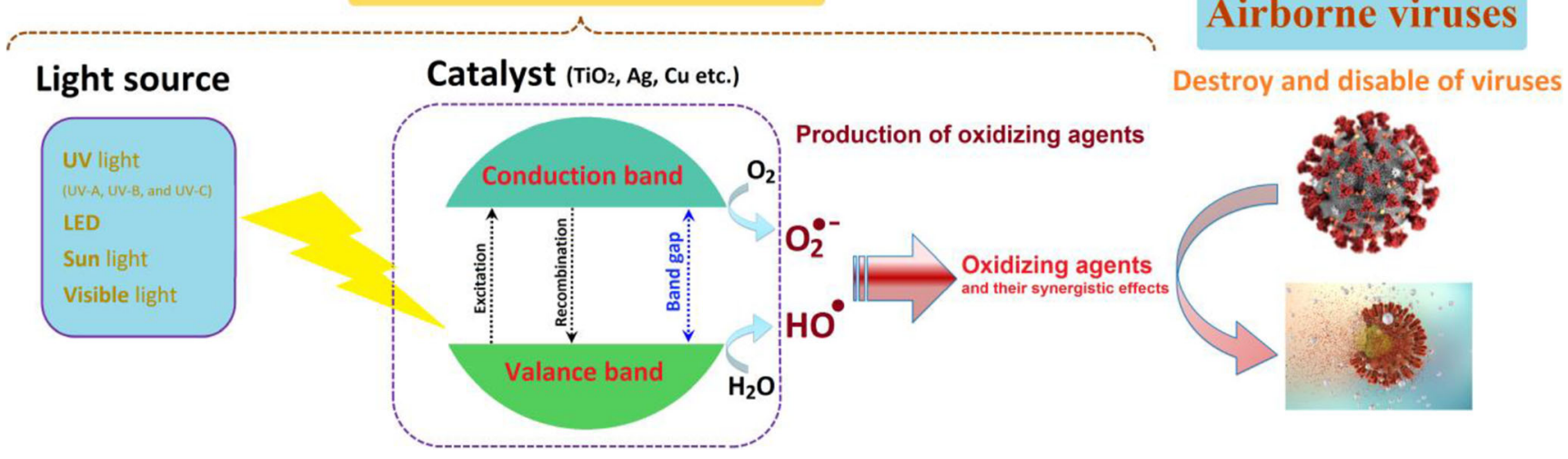

Fig. 1 The suggested major mechanisms for viral inactivation in photocatalytic processes 


$$
2 \mathrm{AgOH} \rightarrow \mathrm{Ag}_{2} \mathrm{O}+\mathrm{H}_{2} \mathrm{O}
$$

The generated $\mathrm{Ag}_{2} \mathrm{O}$ is a thermodynamically stable agent in the $\mathrm{pH}$ range $6-8$, and most of the pathogens are active in this $\mathrm{pH}$ range. Visible light can activate the generated $\mathrm{Ag}_{2} \mathrm{O}$ and thereby produces electrons and holes according to the following equation:

$\mathrm{Ag}_{2} \mathrm{O}+$ light $\rightarrow \mathrm{Ag}_{2} \mathrm{O}_{c b e}{ }^{-}+\mathrm{Ag}_{2} \mathrm{O}_{v b h}{ }^{+}$

Afterwards, the photogenerated radicals are produced according to the following equation:

$e^{-}+\mathrm{O}_{2} \rightarrow \mathrm{O}_{2}^{\cdot}$

$e^{-}+\mathrm{H}^{2} \mathrm{O}+1 / 2 \mathrm{O}_{2} \rightarrow \mathrm{OH}^{\bullet}+\mathrm{OH}^{-}$

$h^{+}+\mathrm{H}_{2} \mathrm{O} \rightarrow \mathrm{OH}^{\bullet}+\mathrm{OH}^{-}$

$\mathrm{O}_{2}{ }^{\cdot}-+\mathrm{H}^{+} \rightarrow \mathrm{H}_{2} \mathrm{O}^{\bullet}$

In the presence of a light source, a higher amount of hydroxyl radicals are produced and consequently results in a faster pathogen inactivation (Rtimi and Kiwi 2021).

$\mathrm{AgOH}+\operatorname{light} \rightarrow \mathrm{Ag}^{*}+\mathrm{OH}^{*}$

Moreover, the main mechanisms of virus inactivation are summarized in the following equations:

$$
\begin{aligned}
& \mathrm{CuO}_{c b e}+\mathrm{O}_{2} \rightarrow \mathrm{CuO}+\mathrm{O}_{2}^{-} \\
& \mathrm{CuO}(2+)_{c b e^{-}} \rightarrow \mathrm{CuO}(1) \mathrm{Cu}^{+} \\
& \mathrm{CuO}\left(\mathrm{Cu}^{+}\right)+\mathrm{O}_{2} \rightarrow \mathrm{CuO}\left(\mathrm{Cu}^{+}\right)+\mathrm{O}_{2}^{-} \\
& \mathrm{CuO}\left(\mathrm{Cu}^{+}\right) \rightarrow \mathrm{Cu}_{\text {Ovacancy }}+\mathrm{Cu}^{+}
\end{aligned}
$$

As shown, by using a photon energy exceeding the band gap of $\mathrm{CuO}$, $\mathrm{ROS} \mathrm{O}_{2}{ }^{--}$is produced or $\mathrm{Cu}^{2+}$ is reduced to $\mathrm{Cu}^{+}$ as a result of the reaction of cbe $e^{-}$and $\mathrm{O}_{2}$ (Rtimi and Kiwi 2021).

The virus inactivation in the $\mathrm{TiO}_{2}$ photocatalysis is conducted according to the following reactions:

$\mathrm{TiO}_{2}+c b e^{-} \rightarrow h v_{c b e}{ }^{-}+h v b^{+}$

The photogenerated electrons and holes in the presence of relative humidity in the environment may undergo charge trapping and act as e- and $\mathrm{h}+$ scavengers, respectively. This reaction results in the formation of $\mathrm{O}^{-\cdot}$ and $\mathrm{OH}^{*}$, respectively. These reactions are presented in the following equation:

$$
\begin{aligned}
& \mathrm{O}_{2}+\mathrm{cbe}^{-} \rightarrow \mathrm{O}^{-\bullet} \\
& \mathrm{Hvb}^{+}+\mathrm{H} 2 \mathrm{O} \rightarrow \mathrm{OH} \cdot+\mathrm{Haq}^{+}
\end{aligned}
$$

In the presence of relative humidity, $\mathrm{O}^{-} \bullet$ and $\mathrm{OH} \bullet$ can further react and produce a hydroperoxyl radical $(\mathrm{OOH} \bullet)$ and hydrogen peroxide $\left(\mathrm{H}_{2} \mathrm{O}_{2}\right)$ as follows:

$\mathrm{O}_{2}{ }^{-\bullet}+\mathrm{H}^{+} \rightarrow \mathrm{OOH} \bullet$

$\mathrm{OH} \bullet+\mathrm{OH} \bullet \rightarrow \mathrm{H}_{2} \mathrm{O}_{2}$

$\mathrm{H}_{2} \mathrm{O}_{2}+\mathrm{cbe}^{-} \rightarrow \mathrm{OH} \bullet+\mathrm{OH}^{-}$

The produced oxygen-centered radicals such as $\mathrm{OOH} \cdot$, $\mathrm{OH} \cdot$, and $\mathrm{O}_{2}{ }^{-} \cdot$ react with organic molecules present in microorganisms like proteins and polyunsaturated fatty acids and hence result in the inactivation of microorganism (Bono et al. 2021).

In this regard, Daikoku et al. indicated nano- $\mathrm{TiO}_{2}$ photocatalytic coated with porous ceramic inactivated influenza virus by decomposition of aldehyde and dioxins and inactivation of aerosol-associated influenza virus infectivity (Daikoku et al. 2015). In a comprehensive review study, it has been reported that $\mathrm{TiO}_{2}$ photocatalysis processes can inactivate viruses through protein damage, resulting in viral capsids, and releasing viral DNA, which cause the degradation of protein and genome. In this case, the inactivation processes of viruses occur in the four following steps, including (a) modification of the protein sequence, (b) disruption of the protein conformation, (c) disruption of the protein aggregated size, and (d) disruption of the binding of spike virus protein to protein to the host cells. In the use of $\mathrm{TiO}_{2}$, the particle size, surface area, porosity, and crystallographic structure affect the levels of generated ROS, which affect the inactivation performance. Yoshizawa et al. used scrubber photocatalytic oxidation and UV irradiation for inactivating infectious bursal disease virus (IBDV). They determined mechanism of UV inactivation of viruses was mainly due to uracil dimerization in viral RNA (Zhao et al. 2014). Moreover, Valdez-Castillo et al. indicted that the photocatalytic system based on $\mathrm{Cu} / \mathrm{TiO}_{2}$ non-woven fabric achieved the highest percentage of bioaerosol inactivation (70\%) caused by cell death (Valdez-Castillo et al. 2019). Nakano et al. showed that $\mathrm{TiO}_{2}$ thin film significantly disinfected the influenza virus through degradation of viral proteins. They realized that the degradation relied on the illumination time of UV and its intensity (Nakano et al. 2012a). The mentioned mechanisms are affected when the photocatalyst surface and the viral particles collide, resulting in an increase of the photocatalytic efficiecny due to the higher production of ROSs (Foster et al. 2011; Gao et al. 2014).

\section{Conclusion}

Photocatalysis processes as promising technology can be used for purifying air containing airborne viruses from indoor air. 
Catalyst type plays a key role in the performance of the photocatalytic processes for the inactivation of airborne viruses. The photocatalytic processes offer various efficiencies for the inactivation of viruses in air, and hence, a constant viral model may not be generalizable to other airborne viruses. Environmental factors including temperature and humidity had distinct effects on the photocatalyst process for the inactivation of viruses by means of changing photocatalytic rate. Chemical oxidation by ROS, toxicity of metal ions released from metal-containing photocatalysts, and morphological damage of airborne viruses by sharp edges of twodimensional nano-structural photocatalysts are considered the main mechanisms for the inactivation of airborne viruses.

Author contribution Ali Poormohammadi: Conceptualization, supervision, writing - review and editing

Fereshteh Mehri: Writing - review and editing

Ghasem Azarian: Conceptualization, writing - review

Ali Reza Rahmani: Conceptualization, writing — original draft

Saed Bashirian: Conceptualization, supervision

Funding This project was financially supported by the Vice-Chancellor for Research and Technology, Hamadan University of Medical Sciences (Grant number: 9904102149).

Data availability All the data and material pertinent to this manuscript are included and have been reviewed by all authors.

\section{Declarations}

Ethics approval and consent to participate Not applicable

Consent for publication Not applicable

Conflict of interest The authors declare no competing interests.

\section{References}

Abbasipour M, Mirjalili M, Khajavi R, Majidi MM (2014) Coated cotton gauze with $\mathrm{Ag} / \mathrm{ZnO} /$ chitosan nanocomposite as a modern wound dressing. Journal of Engineered Fibers and Fabrics 9: 155892501400900114

Abdennouri M, Baâlala M, Galadi A, El Makhfouk M, Bensitel M, Nohair K, Sadiq M, Boussaoud A, Barka N (2016) Photocatalytic degradation of pesticides by titanium dioxide and titanium pillared purified clays. Arab J Chem 9:S313-S318

Abidi M, Assadi A, Bouzaza A, Hajjaji A, Bessais B, Rtimi S (2019) Photocatalytic indoor/outdoor air treatment and bacterial inactivation on $\mathrm{CuxO} / \mathrm{TiO} 2$ prepared by HiPIMS on polyester cloth under low intensity visible light. Appl Catal B Environ 259:118074

Ahmed F, Awada C, Ansari SA, Aljaafari A, Alshoaibi A (2019) Photocatalytic inactivation of Escherichia coli under UV light irradiation using large surface area anatase $\mathrm{TiO} 2$ quantum dots. R Soc Open Sci 6:191444

Al-Sabahi J, Bora T, Al-Abri M, Dutta J (2017) Efficient visible light photocatalysis of benzene, toluene, ethylbenzene and xylene
(BTEX) in aqueous solutions using supported zinc oxide nanorods. PLoS One 12:e0189276-e189276

Arana J, Rodriguez CF, Díaz OG, Melian JH, Pena JP (2005) Role of Cu in the $\mathrm{Cu}-\mathrm{TiO} 2$ photocatalytic degradation of dihydroxybenzenes. Catal Today 101:261-266

Araña J, Fernández Rodríguez C, González Díaz O, Herrera Melián JA, Pérez Peña J (2005) Role of $\mathrm{Cu}$ in the $\mathrm{Cu}$-TiO2 photocatalytic degradation of dihydroxybenzenes. Catal Today 101:261-266

Barbas Arribas C, Rojo Blanco D (2015): Understanding the antimicrobial mechanism of TiO2-based nanocomposite films in a pathogenic Bacterium/David Rojo...[et al.]

Bono N, Ponti F, Punta C, Candiani G (2021) Effect of UV irradiation and $\mathrm{TiO} 2$-photocatalysis on airborne bacteria and viruses: an overview. Materials 14:1075

Byeon JH, Park JH, Hwang J (2008) Spark generation of monometallic and bimetallic aerosol nanoparticles. J Aerosol Sci 39:888-896

Candiani G, Soliani E (n.d.) Photocatalytic activity of titanium dioxide against bacteria and viruses

Cao L, Gao Z, Suib SL, Obee TN, Hay SO, Freihaut JD (2000) Photocatalytic oxidation of toluene on nanoscale $\mathrm{TiO} 2$ catalysts: studies of deactivation and regeneration. J Catal 196:253-261

Chen F, Yang X, Wu Q (2009) Photocatalytic oxidation of Escherischia coli, Aspergillus niger, and formaldehyde under different ultraviolet irradiation conditions. Environ Sci Technol 43:4606-4611

Cho M, Chung H, Yoon J (2003) Disinfection of water containing natural organic matter by using ozone-initiated radical reactions. Appl Environ Microbiol 69:2284-2291

Costacurta S, Maso GD, Gallo R, Guglielmi M, Brusatin G, Falcaro P (2010) Influence of temperature on the photocatalytic activity of sol - gel TiO2 films. ACS Appl Mater Interfaces 2:1294-1298

Daikoku T, Takemoto M, Yoshida Y, Okuda T, Takahashi Y, Ota K, Tokuoka F, Kawaguchi AT, Shiraki K (2015) Decomposition of organic chemicals in the air and inactivation of aerosol-associated influenza infectivity by photocatalysis. Aerosol Air Qual Res 15: $1469-1484$

De Vietro N, Tursi A, Beneduci A, Chidichimo F, Milella A, Fracassi F, Chatzisymeon E, Chidichimo G (2019) Photocatalytic inactivation of Escherichia coli bacteria in water using low pressure plasma deposited TiO 2 cellulose fabric. Photochem Photobiol Sci 18: $2248-2258$

Dennehy JJ (2009) Bacteriophages as model organisms for virus emergence research. Trends Microbiol 17:450-457

Einaga H, Ibusuki T, Futamura S (2004) Photocatalytic oxidation of benzene in air. Journal of Solar Energy Engineering 126:789-793

Foster HA, Ditta IB, Varghese S, Steele A (2011) Photocatalytic disinfection using titanium dioxide: spectrum and mechanism of antimicrobial activity. Appl Microbiol Biotechnol 90:1847-1868

Gao P, Li A, Sun DD, Ng WJ (2014) Effects of various TiO2 nanostructures and graphene oxide on photocatalytic activity of $\mathrm{TiO} 2$. J Hazard Mater 279:96-104

Gerrity D, Ryu H, Crittenden J, Abbaszadegan M (2008) Photocatalytic inactivation of viruses using titanium dioxide nanoparticles and lowpressure UV light. J Environ Sci Health A 43:1261-1270

Ghezzi S, Pagani I, Poli G, Perboni S, Vicenzi E (2020) Rapid inactivation of severe acute respiratory syndrome coronavirus 2 (SARSCoV-2) by tungsten trioxide-based (WO3) photocatalysis. bioRxiv

Goswami DY, Trivedi DM, Block S (1997) Photocatalytic disinfection of indoor air

Habibi-Yangjeh A, Asadzadeh-Khaneghah S, Feizpoor S, Rouhi A (2020) Review on heterogeneous photocatalytic disinfection of waterborne, airborne, and foodborne viruses: can we win against pathogenic viruses? Journal of Colloid and Interface Science

Hajkova P, Spatenka P, Horsky J, Horska I, Kolouch A (2007) Photocatalytic effect of TiO2 films on viruses and bacteria. Plasma Process Polym 4:S397-S401 
Harmooshi NN, Shirbandi K, Rahim F (2020) Environmental concern regarding the effect of humidity and temperature on 2019-nCoV survival: fact or fiction. Environ Sci Pollut Res Int 27:36027-36036

Hitchman ML (2020) A new perspective of the chemistry and kinetics of inactivation of COVID -19 coronavirus aerosols. Futur Virol 15: 823-835. https://doi.org/10.2217/fvl-2020-0326

Ishiguro H, Nakano R, Yao Y, Kajioka J, Fujishima A, Sunada K, Minoshima M, Hashimoto K, Kubota Y (2011) Photocatalytic inactivation of bacteriophages by TiO 2-coated glass plates under lowintensity, long-wavelength UV irradiation. Photochem Photobiol Sci 10:1825-1829

Jacoby WA, Maness PC, Wolfrum EJ, Blake DM, Fennell JA (1998) Mineralization of bacterial cell mass on a photocatalytic surface in air. Environ Sci Technol 32:2650-2653

Jafari AJ, Kalantari RR, Kermani M, Firooz MH (2019) Photocatalytic oxidation of benzene by $\mathrm{ZnO}$ coated on glass plates under simulated sunlight. Chem Pap 73:635-644

Jafry HR, Liga MV, Li Q, Barron AR (2011) Simple route to enhanced photocatalytic activity of $\mathrm{P} 25$ titanium dioxide nanoparticles by silica addition. Environ Sci Technol 45:1563-1568

Jensen MM (1964) Inactivation of airborne viruses by ultraviolet irradiation. Appl Microbiol 12:418-420

Joe YH, Park DH, Hwang J (2016) Evaluation of Ag nanoparticle coated air filter against aerosolized virus: anti-viral efficiency with dust loading. J Hazard Mater 301:547-553

Josset S, Taranto J, Keller N, Keller V, Lett M-C, Ledoux MJ, Bonnet V, Rougeau S (2007) UV-A photocatalytic treatment of high flow rate air contaminated with Legionella pneumophila. Catal Today 129: 215-222

Kadam AN, Kim TG, Shin DS, Garadkar KM, Park J (2017) Morphological evolution of $\mathrm{Cu}$ doped $\mathrm{ZnO}$ for enhancement of photocatalytic activity. J Alloys Compd 710:102-113

Kanakaraju D, Glass BD, Oelgemöller M (2018) Advanced oxidation process-mediated removal of pharmaceuticals from water: a review. J Environ Manag 219:189-207

Khaiboullina S, Uppal T, Dhabarde N, Subramanian VR, Verma SC (2020) Inactivation of human coronavirus by titania nanoparticle coatings and UVC radiation: throwing Light on SARS-CoV-2. 13

Kim J, Jang J (2018) Inactivation of airborne viruses using vacuum ultraviolet photocatalysis for a flow-through indoor air purifier with short irradiation time. Aerosol Sci Technol 52:557-566

Kim S-H, Shahbaz HM, Park D, Chun S, Lee W, Oh J-W, Lee D-U, Park J (2017) A combined treatment of UV-assisted TiO2 photocatalysis and high hydrostatic pressure to inactivate internalized murine norovirus. Innovative Food Sci Emerg Technol 39:188-196

Kormuth KA, Lin K, Prussin AJ, Vejerano EP, Tiwari AJ, Cox SS, Myerburg MM, Lakdawala SS, Marr LC (2018) Influenza virus infectivity is retained in aerosols and droplets independent of relative humidity. J Infect Dis 218:739-747

Kumar SG, Devi LG (2011) Review on modified TiO2 photocatalysis under UV/visible light: selected results and related mechanisms on interfacial charge carrier transfer dynamics. J Phys Chem A 115: 13211-13241

Lee BU (2011) Life comes from the air: a short review on bioaerosol control. Aerosol Air Qual Res 11:921-927

Li X, Xie J, Jiang C, Yu J, Zhang P (2018) Review on design and evaluation of environmental photocatalysts. Frontiers of Environmental Science \& Engineering 12:14

Liang WJ, Li J, Jin YQ (2010) Photocatalytic degradation of gaseous acetone, toluene, and p-xylene using a $\mathrm{TiO} 2$ thin film. Journal of Environmental Science and Health Part A 45:1384-1390

Liga MV, Bryant EL, Colvin VL, Li Q (2011) Virus inactivation by silver doped titanium dioxide nanoparticles for drinking water treatment. Water Res 45:535-544

Lin C-Y, Li C-S (2003) Inactivation of microorganisms on the photocatalytic surfaces in air. Aerosol Sci Technol 37:939-946
Linga Reddy E, Karuppiah J, Biju V, Subrahmanyam C (2013) Catalytic packed bed non-thermal plasma reactor for the extraction of hydrogen from hydrogen sulfide. Int J Energy Res 37:1280-1286

Liu M, Sunada K, Hashimoto K, Miyauchi M (2015) Visible-light sensitive $\mathrm{Cu}$ (II)-TiO 2 with sustained anti-viral activity for efficient indoor environmental remediation. J Mater Chem A 3:17312-17319

Long B, Huang J, Wang X (2012) Photocatalytic degradation of benzene in gas phase by nanostructured BiPO4 catalysts. Progress in Natural Science: Materials International 22:644-653

Mamaghani AH, Haghighat F, Lee C-S (2017) Photocatalytic oxidation technology for indoor environment air purification: the state-of-theart. Appl Catal B Environ 203:247-269

Marambio-Jones C, Hoek EM (2010) A review of the antibacterial effects of silver nanomaterials and potential implications for human health and the environment. J Nanopart Res 12:1531-1551

Mehdizadeh P, Tavangar Z (2017) Photocatalyst Ag@ N/TiO2 nanoparticles: fabrication, characterization, and investigation of the effect of coating on methyl orange dye degradation. Journal of Nanostructures 7:216-222

Miyauchi M, Sunada K, Hashimoto K (2020) Antiviral effect of visible light-sensitive $\mathrm{CuxO} / \mathrm{TiO} 2$ photocatalyst. Catalysts 10:1093

Moon EW, Lee H-W, Rok JH, Ha J-H (2020) Photocatalytic inactivation of viral particles of human norovirus by $\mathrm{Cu}$-doped $\mathrm{TiO} 2$ non-woven fabric under UVA-LED wavelengths. Sci Total Environ 749: 141574

Moongraksathum B, Chien M-Y, Chen Y-W (2019) Antiviral and antibacterial effects of silver-doped $\mathrm{TiO} 2$ prepared by the peroxo sol-gel method. J Nanosci Nanotechnol 19:7356-7362

Nakano R, Ishiguro H, Yao Y, Kajioka J, Fujishima A, Sunada K, Minoshima M, Hashimoto K, Kubota Y (2012a) Photocatalytic inactivation of influenza virus by titanium dioxide thin film. Photochem Photobiol Sci 11:1293-1298

Nakano R, Ishiguro H, Yao Y, Kajioka J, Fujishima A, Sunada K, Minoshima M, Hashimoto K, Kubota Y (2012b) Photocatalytic inactivation of influenza virus by titanium dioxide thin film. Photochemical \& photobiological sciences : official journal of the European Photochemistry Association and the European Society for Photobiology 11:1293-1298

Ornstein JM, Ozdemir R, Boehme A, Serre C, Nouar F, Santarpia J, Herrera VL, Ackerman DN (2020) SARS-CoV-2 inactivation potential of metal organic framework induced photocatalysis. medRxiv

Papadaki D, Mhlongo GH, Motaung DE, Nkosi SS, Panagiotaki K, Christaki E, Assimakopoulos MN, Papadimitriou VC, Rosei F, Kiriakidis G (2019) Hierarchically porous $\mathrm{Cu}-, \mathrm{Co}-$, and $\mathrm{Mn}$ doped platelet-like $\mathrm{ZnO}$ nanostructures and their photocatalytic performance for indoor air quality control. ACS omega 4:16429-16440

Prasher P, Singh M, Mudila H (2018) Oligodynamic effect of silver nanoparticles: a review. BioNanoScience 8:951-962

Principi N, Silvestri E, Esposito S (2019) Advantages and limitations of bacteriophages for the treatment of bacterial infections. Front Pharmacol 10:513

Qiao Y, Yang M, Marabella IA, McGee DA, Aboubakr H, Goyal S, Hogan Jr CJ, Olson BA, Torremorell M (2020a) Greater than 3$\log$ reduction in viable coronavirus aerosol concentration in ducted ultraviolet-C (UV-C) systems. Environmental science \& technology

Qiao Y, Yang M, Marabella IA, McGee DAJ, Aboubakr H, Goyal S, Hogan CJ, Jr., Olson BA, Torremorell M (2020b) Greater than 3-log reduction in viable coronavirus aerosol concentration in ducted ultraviolet-C (UV-C) systems. Environmental science \& technology, acs.est.0c05763

Rahimi S, Poormohammadi A, Salmani B, Ahmadian M, Rezaei M (2016) Comparing the photocatalytic process efficiency using batch and tubular reactors in removal of methylene blue dye and COD 
from simulated textile wastewater. Journal of Water Reuse and Desalination 6:574-582

Rahmani AR, Leili M, Azarian G, Poormohammadi A (2020) Sampling and detection of corona viruses in air: a mini review. Sci Total Environ 740:140207

Rtimi S, Kiwi J (2021) Update on interfacial charge transfer (IFTC) processes on films inactivating viruses/bacteria under visible light: mechanistic considerations and critical issues. Catalysts 11:201

Rtimi S, Dionysiou DD, Pillai SC, Kiwi J (2019) Advances in catalytic/ photocatalytic bacterial inactivation by nano $\mathrm{Ag}$ and $\mathrm{Cu}$ coated surfaces and medical devices. Appl Catal B Environ 240:291-318

Sakka S (2013) Handbook of Advanced Ceramics: Chapter 11.1. 2. SolGel Process and Applications. Elsevier Inc. Chapters

Samarghandi MR, Babaee SA, Ahmadian M, Asgari G, Ghorbani Shahna F, Poormohammadi A (2014) Performance catalytic ozonation over the carbosieve in the removal of toluene from waste air stream. Journal of research in health sciences 14:227-232

Samarghandi MR, Daraee Z, Shekher Giri B, Asgari G, Reza Rahmani A, Poormohammadi A (2017) Catalytic ozonation of ethyl benzene using modified pumice with magnesium nitrate from polluted air. Int J Environ Stud 74:486-499

Shiraki K, Yamada H, Yoshida Y, Ohno A, Watanabe T, Watanabe T, Watanabe H, Watanabe H, Yamaguchi M, Tokuoka F (2017) Improved photocatalytic air cleaner with decomposition of aldehyde and aerosol-associated influenza virus infectivity in indoor air. Aerosol Air Qual Res 17:2901-2912

Singh M, Jampaiah D, Kandjani AE, Sabri YM, Della Gaspera E, Reineck P, Judd M, Langley J, Cox N, van Embden J (2018) Oxygen-deficient photostable $\mathrm{Cu} 2 \mathrm{O}$ for enhanced visible light photocatalytic activity. Nanoscale 10:6039-6050

Smither SJ, Lear-Rooney C, Biggins J, Pettitt J, Lever MS, Olinger GG (2013) Comparison of the plaque assay and 50\% tissue culture infectious dose assay as methods for measuring filovirus infectivity. J Virol Methods 193:565-571

Szeto W, Yam WC, Huang H, Leung DYC (2020) The efficacy of vacuum-ultraviolet light disinfection of some common environmental pathogens. BMC Infect Dis 20:127

Tang JW (2009): The effect of environmental parameters on the survival of airborne infectious agents. J R Soc Interface 6 Suppl 6, S737S746

Tri NLM, Duc DS, Van Thuan D, Al Tahtamouni T, Pham T-D, Tran DT, Le Chi NTP (2019) Superior photocatalytic activity of $\mathrm{Cu}$ doped NiWO4 for efficient degradation of benzene in air even under visible radiation. Chem Phys 525:110411

Tsang CHA, Li K, Zeng Y, Zhao W, Zhang T, Zhan Y, Xie R, Leung DY, Huang H (2019) Titanium oxide based photocatalytic materials development and their role of in the air pollutants degradation: overview and forecast. Environ Int 125:200-228

Valdez-Castillo M, Saucedo-Lucero JO, Arriaga S (2019) Photocatalytic inactivation of airborne microorganisms in continuous flow using perlite-supported $\mathrm{ZnO}$ and $\mathrm{TiO} 2$. Chem Eng J 374:914-923

Visai L, De Nardo L, Punta C, Melone L, Cigada A, Imbriani M, Arciola CR (2011) Titanium oxide antibacterial surfaces in biomedical devices. The International journal of artificial organs 34:929-946

Wang D, Oppenländer T, El-Din MG, Bolton JR (2010) Comparison of the disinfection effects of vacuum-UV (VUV) and UV light on Bacillus subtilis spores in aqueous suspensions at 172, 222 and $254 \mathrm{~nm}$. Photochem Photobiol 86:176-181

Wu M-C, Wu P-Y, Lin T-H, Lin T-F (2018) Photocatalytic performance of Cu-doped $\mathrm{TiO} 2$ nanofibers treated by the hydrothermal synthesis and air-thermal treatment. Appl Surf Sci 430:390-398

Yang L, Zhou H, Fan T, Zhang D (2014) Semiconductor photocatalysts for water oxidation: current status and challenges. Phys Chem Chem Phys 16:6810-6826

Yin Y, Xu Y, Ou Z, Su L, Xia H (2015) A simple and highly repeatable viral plaque assay for enterovirus 71. J Basic Microbiol 55:538-541

Yoshizawa N, Ishihara R, Omiya D, Ishitsuka M, Hirano S, Suzuki T (2020) Application of a photocatalyst as an inactivator of bovine coronavirus. Viruses 12:1372

Yu K-P, Lee GW-M, Lin S-Y, Huang CP (2008) Removal of bioaerosols by the combination of a photocatalytic filter and negative air ions. $\mathrm{J}$ Aerosol Sci 39:377-392

Yu Y, Wen W, Qian X-Y, Liu J-B, Wu J-M (2017) UV and visible light photocatalytic activity of $\mathrm{Au} / \mathrm{TiO} 2$ nanoforests with anatase/rutile phase junctions and controlled Au locations. Sci Rep 7:1-13

Zan L, Fa W, Peng T, Z-k G (2007) Photocatalysis effect of nanometer $\mathrm{TiO} 2$ and $\mathrm{TiO} 2$-coated ceramic plate on hepatitis B virus. J Photochem Photobiol B Biol 86:165-169

Zhao Y, Aarnink AJ, Xin H (2014) Inactivation of airborne Enterococcus faecalis and infectious bursal disease virus using a pilot-scale ultraviolet photocatalytic oxidation scrubber. J Air Waste Manage Assoc 64:38-46

Zheng X, Shen ZP, Cheng C, Shi L, Cheng R, Yuan DH (2018) Photocatalytic disinfection performance in virus and virus/bacteria system by $\mathrm{Cu}-\mathrm{TiO}(2)$ nanofibers under visible light. Environmental pollution (Barking, Essex : 1987) 237, 452-459

Publisher's note Springer Nature remains neutral with regard to jurisdictional claims in published maps and institutional affiliations. 